\title{
Optimal diet selection by white-tailed deer: balancing reproduction with starvation risk
}

\author{
OSWALD J. SCHMITZ* \\ School of Natural Resources, The University of Michigan, Ann Arbor, MI 48109-1115, USA
}

\section{Summary}

Energy intake rates of wintering deer vary over time because of variation in the abundance and quality of their natural foods. Accordingly, there is a chance that energy requirements will not be satisfied in a feeding period. This is especially critical because deer are reproductive during winter; hence selecting diets to minimize the risk of starvation may not maximize fitness. I examined diet selection by white-tailed deer (Odocoileus virginianus) using a risk-sensitive foraging model which predicts the optimal diet when foragers face starvation risks during a reproductive period. Optimal diets were estimated by quantifying the mean and variance in energy intake rate deer could obtain when selecting different potential diets and substituting these values into functions for estimating offspring production and starvation risk. I conducted a field experiment to ask whether deer selected deciduous and coniferous twigs according to model predictions. Starvation risk was manipulated by providing deer supplemental feed. When faced with starvation risks, deer appeared to select diets that balanced offspring production with starvation risk. When starvation risk was eliminated, deer tended to select diets that simply maximized their mean energy intake rates.

Keywords: deer; foraging experiment; optimal diet; risk-sensitive foraging; twig selection

\section{Introduction}

Optimal foraging models relate fitness (survival and reproduction) to particular decisions in order to identify the basis of animal foraging behaviour. Traditional theories, such as the classical foraging model (Stephens and Krebs, 1986), assume that fitness increases with a forager's expected nutrient intake rate. Any variance in nutrient intake rate is assumed to be negligible or unimportant. Consequently, foragers are predicted to select diets that maximize their expected nutrient intake rate to maximize fitness (Schoener, 1974; Stephens and Krebs, 1986).

If, however, the variance in nutrient intake rate for a diet is sufficiently large, there is a risk that a forager's nutrient intake rate may not satisfy its nutrient requirements per unit time (Real and Caraco, 1986; Stephens and Krebs, 1986). Consequently, selecting diets simply to maximize expected nutrient intake rate may not maximize fitness; both mean and variance in nutrient intake rate become important in decision-making. Foragers may then select diets with the meanvariance combination that minimizes or avoids starvation risk, called risk-sensitive foraging (Real and Caraco, 1986; Stephens and Krebs, 1986).

In most experimental tests of risk-sensitive foraging theory, the researcher specified the magnitude of variation in nutrient intake rate the forager obtained (Real and Caraco, 1986; Stephens and Krebs, 1986; Barkan, 1990). Although foragers have responded predictably to

* Present Address: Department of Zoology, University of British Columbia, Vancouver, British Columbia, Canada V6T $1 \mathrm{Z4}$. 
these manipulations, it is still not clear if risk-sensitive foraging theory applies in natural environments. This is because it is still largely unknown whether the magnitude of variance in nutrient intake rate in natural foraging environments is sufficient to introduce the kinds of risks encountered in more artificial conditions (Houston and McNamara, 1985).

Generalist herbivores such as wintering deer are potentially suitable candidates for examining the relevance of risk-sensitive foraging in natural environments. Deer encounter considerable spatial and temporal variation in plant nutrient quality and abundance (Belovsky, 1981; OwenSmith and Novellie, 1982; Danell and Ericson, 1986; Vivas and Saether, 1987). This can cause variance in daily nutrient intake to be large enough that deer will fail to satisfy daily nutrient requirements (Schmitz, 1990). Also, deer at northern latitudes are known to starve during winter (Mautz, 1978).

Previous risk-sensitive models (e.g. Caraco, 1980; Real, 1981; Stephens and Charnov, 1982), however, may not be appropriate for predicting diet selection by deer. This is because the models assume that survival (starvation risk) is the only component of fitness (but see Caraco and Gillespie, 1986). Consequently, optimal diets are predicted for a single goal of risk minimization. But, wintering deer potentially have two conflicting foraging goals.

First, adult female deer are often pregnant during winter. Individuals which obtain higher daily nutrient intake rates have higher net offspring production (Verme, 1967, 1969; Langeneau and Lerg, 1976). Also, fawns grow during winter and growth rate is correlated with nutrient intake rate (Baker et al., 1979; Holter et al., 1979). Increased growth increases size at maturity and may consequently increase fitness (survival and reproduction) (Robinson, 1962; Townsend, 1973; Clutton-Brock et al., 1982). Second, it is theoretically possible that diets providing the greatest mean nutrient intake rates have higher associated variances, and thus greater starvation risks than diets with lower mean nutrient intake rates (Houston and McNamara, 1985; Schmitz and Ritchie, 1991).

Consequently, diets that maximize growth or offspring production may present deer with high starvation risks. But diets with low risks of starvation may result in decreased growth or offspring production. To maximize fitness, deer may have to balance a trade-off between maximizing growth/offspring production and minimizing risk. Schmitz and Ritchie (1991) developed a foraging model which predicts the diet that balances such a trade-off. I tested whether whitetailed deer selected their diet in accordance with predictions of this model. Twig selection was examined using an experiment which manipulated the potential risk of starvation in natural foraging environments using supplemental feed.

\section{The foraging model}

In the foraging model (Schmitz and Ritchie, 1991), $m$ defines the minimum nutrient quality (KJ $(\text { item })^{-1}$ ) a forager should include in its diet (i.e. the diet breadth) and $\epsilon(m)$ defines the nutrient intake rate for a given diet breadth in a feeding period $T_{f}$. Let $E[\epsilon(m)]$ and $V[\epsilon(m)]$ be the mean and variance in nutrient intake rate, for a diet breadth, estimated for $k$ feeding periods within the time interval $\left[T_{1}, T_{k}\right]$. The mean and variance are substituted into a function relating nutrient intake rate to offspring production, $f\{\epsilon(m)\}$. This is used to estimate the forager's expected offspring production for different diet breadths $E[f\{\epsilon(m)\}]$ for the interval $\left[T_{1}, T_{k}\right]$ (Schmitz and Ritchie, 1991). Mean and variance in nutrient intake rate are also used to estimate the starvation risk for each diet breadth $D(m)$ over the same time interval (Schmitz and Ritchie, 1991).

Expected offspring production and starvation risk can be combined to estimate fitness for different diet breadths $W(m)$. Fitness is estimated as:

$$
W(m)=E[f\{\epsilon(m)\}] S(m)
$$




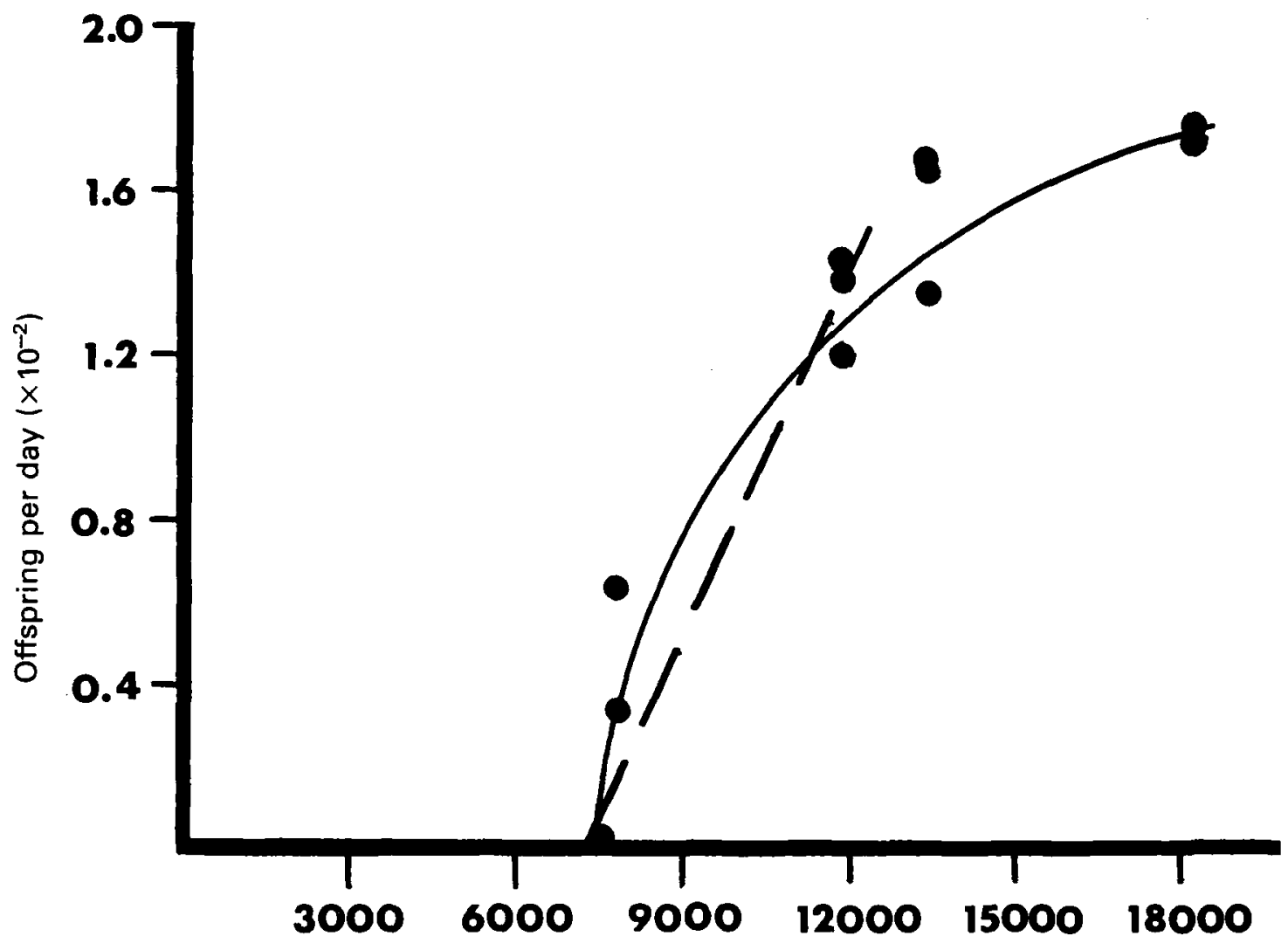

Energy intake (KJ day ${ }^{-1}$ )

Figure 1. Estimated offspring production by captive white-tailed deer in spring in relation to daily energy intake rate (data from Verme 1962, 1965, 1967, 1969). In these studies, groups of deer were provided specific levels of feed over the winter and the associated offspring production was measured in spring. The nonlinear regression for the complete data set (solid line) is $Y=0.029-203.7 / X\left(R^{2}=0.89, n=11\right)$. However, deer in the study area can only obtain a maximum of $9000 \mathrm{KJ}$ daily when feeding on browse (Schmitz, 1990). The best fit regression line is linear over this range of possible energy intake rates (dashed line) and is $Y=0.0000024 X-0.0153\left(R^{2}=0.84, n=6\right)$.

where $S(m)=1-D(m)$, the probability of survival. The optimal diet is determined by $\hat{m}$ such that $d W / d m=0$. The condition for the optimum is (Schmitz and Ritchie, 1991):

$$
\frac{E[d f\{\epsilon(m)\} / d m]}{E[f\{\epsilon(m)\}]}=\frac{-d S(m) / d m}{S(m)}
$$

Equation 2 reduces to previous diet models when specific assumptions are imposed. If foragers are not reproductive, the optimum is obtained when $-[d S(m) / d m] / S(m)=0$. This is the starvation-risk minimizing diet breadth. When starvation risk is negligible the optimum occurs when $E[d f\{\epsilon(m)\}] / d m / E[f\{\epsilon(m)\}]=0$. When $f\{\epsilon(m)\}$ is linear, this is the classical optimal diet.

For white-tailed deer, $f\{\epsilon(m)\}$ is approximately linear over the potential range of energy intake 
rates they could obtain in natural wintering environments (Fig. 1). Accordingly, the following predictions emerge for the study system:

1. Deer encountering starvation risks should select diet breadths that balance gains in fitness due to reproduction with losses in fitness due to starvation risk. These diet breadths will be intermediate to risk minimizing and classical optimal diet breadths (Schmitz and Ritchie, 1991). 2. If starvation risk is eliminated, deer should select the diet breadths maximizing mean nutrient intake rates.

\section{Experimental design}

To test the model predictions, I conducted an experiment in $2,1 \mathrm{~km}^{2}$ areas in the Loring Deer Yard in east-central Ontario, Canada (see Schmitz, 1990, 1991). I examined diet selection for each of two principal kinds of foods, deciduous and coniferous twigs (Schmitz, 1990), in three replicate browse patches within each $1 \mathrm{~km}^{2}$ area.

The experiment was designed to test for responses to two kinds of environmental changes on starvation risk. First, I examined the effect of increasing starvation risk due to natural changes in the foraging environment. This was examined in one, $1 \mathrm{~km}^{2}$ area (natural wintering treatment) where deer only had access to natural browse for the entire winter. Deer were expected to encounter risks of starvation given the magnitude of the mean and variance in energy intake rate deer have achieved in this environment (Schmitz, 1990). Moreover, starvation risk increased over time because browse depletion and increasing snow levels decreased the abundance of twigs (Schmitz, 1990). Deciduous twig selection was examined in three arbitrary 30-day sampling periods with different snow levels and twig abundances (Schmitz, 1990): (1) early winter; (2) midwinter; and (3) late winter. Coniferous twig selection was only examined in early and mid-winter because of logistical limitations. Second, starvation risk was eliminated artificially in another 1 $\mathrm{km}^{2}$ area (supplemental feeding treatment) by feeding deer ad libitum amounts of corn and oats for the entire winter. Supplemental feed was not delivered near experimental browse plots (Schmitz, 1990).

\section{Solving the foraging model}

I estimated the optimal diets for each treatment area, replicate food patch and time period by quantifying the mean and variance in nutrient intake rates for different potential diet breadths given the abundance and quality of foods in each foraging environment. I solved the model using energy as the currency for fitness because previous studies suggested energy was, on average, most limiting for deer wintering at northern latitudes (Mautz, 1978; Potvin and Huot, 1983; Robbins 1983; Hanley and McKendrick, 1985).

\section{Estimating energy intake rate}

To select the appropriate model for calculating energy intake rates it is essential to know how deer encountered individual twigs. In the study area, deciduous and coniferous twigs occurred in separate patches (Schmitz, 1990), so I examined diet selection for these twigs separately. The frequency distributions of deciduous or coniferous twigs per $1 \mathrm{~m}$ radius plot within patches were not significantly different from those generated by Poisson density functions with the same mean twig densities $\left(\chi^{2}, p<0.05\right)$. Thus, deer randomly encountered individual deciduous or coniferous twigs within a patch. Also, when searching for food items, deer would, upon encountering a twig, smell it and either consume it or move to the next twig and repeat the sampling process. This indicates that decisions about the suitability of twigs were made on a 
sequential-encounter basis. Moreover, the time between encounter and acceptance or rejection of a twig was almost instantaneous ( $<1 \mathrm{~s}$, unpublished observations) so recognition time (Hughes, 1979) would not be an important factor in estimating energy intake rate. These conditions made the classical foraging model (Stephens and Krebs, 1986) most suitable for estimating energy intake rates for different potential diet breadths.

For herbivores, two forms of the classical model are appropriate. The first (Schoener, 1974) assumes that energy intake rate for a diet breadth, $\epsilon(m)$, will be limited by search and handling time for food items where

$$
\epsilon(m)=\frac{\sum_{h}^{m} e_{i} p_{i}}{T s+\sum_{h}^{m} t_{i} p_{i}}
$$

The second (Belovsky, 1984) assumes energy intake rate is limited by digestive time where

$$
\epsilon(m)=\frac{\sum_{h}^{m} e_{i} p_{i}}{\sum_{h}^{m} d_{i} p_{i}}
$$

and $h$ is the highest quality category included in the diet. Energy intake rate for a diet breadth will be the smaller of the two values provided by Equations 3 .

To solve Equations $3 \mathrm{~A}$ and $3 \mathrm{~B}, \mathrm{I}$ estimated $e_{i}$, the digestible energy content of foods from category $i ; p_{i}$, the relative number of food items from category $i$ in the environment; $t_{i}$, the handling time for items from category $i$; Ts, the mean search time for all food items; and $d_{i}$, the digestive time for food items from category $i$ using field measurements or data from the literature.

\section{Digestible energy content $\left(e_{i}, K J\right.$ per item)}

Deciduous twig samples were obtained from $18,1 \mathrm{~m}$ radius plots in each browse patch in the 1 $\mathrm{km}^{2}$ areas. Plot sites were randomly selected within each patch. Coniferous twigs were obtained from wind-fallen trees or from standing trees within the reach of deer $(2 \mathrm{~m}$ above snow crust; unpublished observations). I sampled twigs within $1 \mathrm{~m}$ radius areas on each tree. I clipped 10 deciduous twigs from each $1 \mathrm{~m}$ radius plot within $2 \mathrm{~m}$ above the snow crust layer supporting deer. Twigs were clipped at the junction with a main branch or $20 \mathrm{~cm}$ whichever was shorter (this was 5 $\mathrm{cm}$ longer than the maximum twig length deer consumed; O. J. Schmitz, unpublished observations). I also randomly clipped 10 twigs from each $1 \mathrm{~m}$ radius area on conifer trees. Twigs were dried at $60^{\circ} \mathrm{C}$ for $48 \mathrm{~h}$ and weighed to estimate twig mass.

Gross energy estimates for each twig species were obtained using bomb calorimetry. I measured the digestibility (proportion of dry mass digested) of individual twigs using in vitro digestion in acid/pepsin (Tilley and Terry, 1963; Spalinger, 1980). Although twig digestibility is best analysed in vivo using fistulated deer (Robbins, 1983; Spalinger et al., 1986; Baker and Hobbs, 1987), this method was logistically impossible for analysing all twigs individually $(n=2160)$. The in vitro method only provided an index of digestibility. I converted in vitro digestibilities into expected in vivo values using a regression equation (see Schmitz, 1990). 
I estimated the quality of twig $y$ of species $x\left(e_{x y}\right)$ as

$$
e_{x y}=K_{x} D_{y} W_{y}
$$

where $K_{x}$ is the average gross energy content of twig species $x$, and $D_{y}$ and $W_{y}$ are the in vivo digestibility and dry mass of twig $y$ respectively. Each $e_{x y}$ value was assigned to arbitrarily set quality categories $e_{i}$.

\section{Relative abundance of twig quality category $i\left(p_{i}\right)$}

The relative abundance of twig quality category $i$ was obtained by constructing the frequency distributions of twig qualities per food patch.

Table 1. Mean and standard deviation in estimated twig qualities (KJ(item $\left.)^{-1}\right)$ in replicate twig patches in the Loring study area.

\begin{tabular}{|c|c|c|c|}
\hline Replicate & $n$ (twigs) & $\begin{array}{l}\text { Supplemental } \\
\text { feeding }\end{array}$ & $\begin{array}{l}\text { Natural } \\
\text { wintering }\end{array}$ \\
\hline \multicolumn{4}{|c|}{ Deciduous twigs } \\
\hline 1 & 180 & $1.18(0.63)$ & $0.93(0.50)$ \\
\hline 2 & 180 & $1.21(0.60)$ & $1.08(0.63)$ \\
\hline 3 & 180 & $1.25(0.51)$ & $1.18(0.75)$ \\
\hline \multicolumn{4}{|c|}{ Coniferous twigs } \\
\hline 1 & 180 & $1.82(1.06)$ & $1.72(1.03)$ \\
\hline 2 & 180 & $2.08(2.02)$ & $2.01(1.90)$ \\
\hline 3 & 180 & $1.90(1.38)$ & $1.75(2.07)$ \\
\hline
\end{tabular}

Table 1 presents the mean and standard deviations in twig quality for each deciduous and coniferous patch. Example distributions of twig nutrient quality are presented in Fig. 2. There were no significant differences in mean item quality between natural wintering and supplemental feeding areas for both deciduous and coniferous twigs ( $t$-tests, $p>0.05$ ).

Handling time ( $t_{i}$, min per item)

Using binoculars, I measured handling time, time to bite, chew and swallow a twig, by observing deer feeding on individual twigs. I obtained 50 handling times for each of deciduous and coniferous twigs. Handling time per twig was $0.038 \pm 0.009 \mathrm{~min}$ and $0.034 \pm 0.010 \mathrm{~min}$ for deciduous and coniferous twigs respectively. Variation in handling time $(C . V .=0.27)$ was much smaller than variation in twig mass $(C . V .=0.45)$. Therefore, $I$ assumed handling time was the same for all deciduous or coniferous food categories.

\section{Search time (Ts, min per item)}

Mean search time was estimated as the inverse of mean encounter rate. To estimate encounter rate (twigs $(\mathrm{min})^{-1}$ ) with deciduous or coniferous twigs, whether eaten or not, I obtained the product of average travel velocity $\left(\mathrm{m}(\mathrm{min})^{-1}\right)$, average search width $(\mathrm{m})$ and twig density (items $\mathrm{m}^{-2}$ ). I measured travel rates by observing deer move between two landmarks (e.g. trees) while searching for but not cropping twigs. The exact distance travelled was subsequently measured with a tape measure. I estimated search width by measuring the maximum horizontal distance on both sides of the travel path that deer consumed a twig. This was measured at 10 random points along each travel path and averaged. I measured twig densities by counting all deciduous twigs in 


\section{Deciduous}

\section{Coniferous}

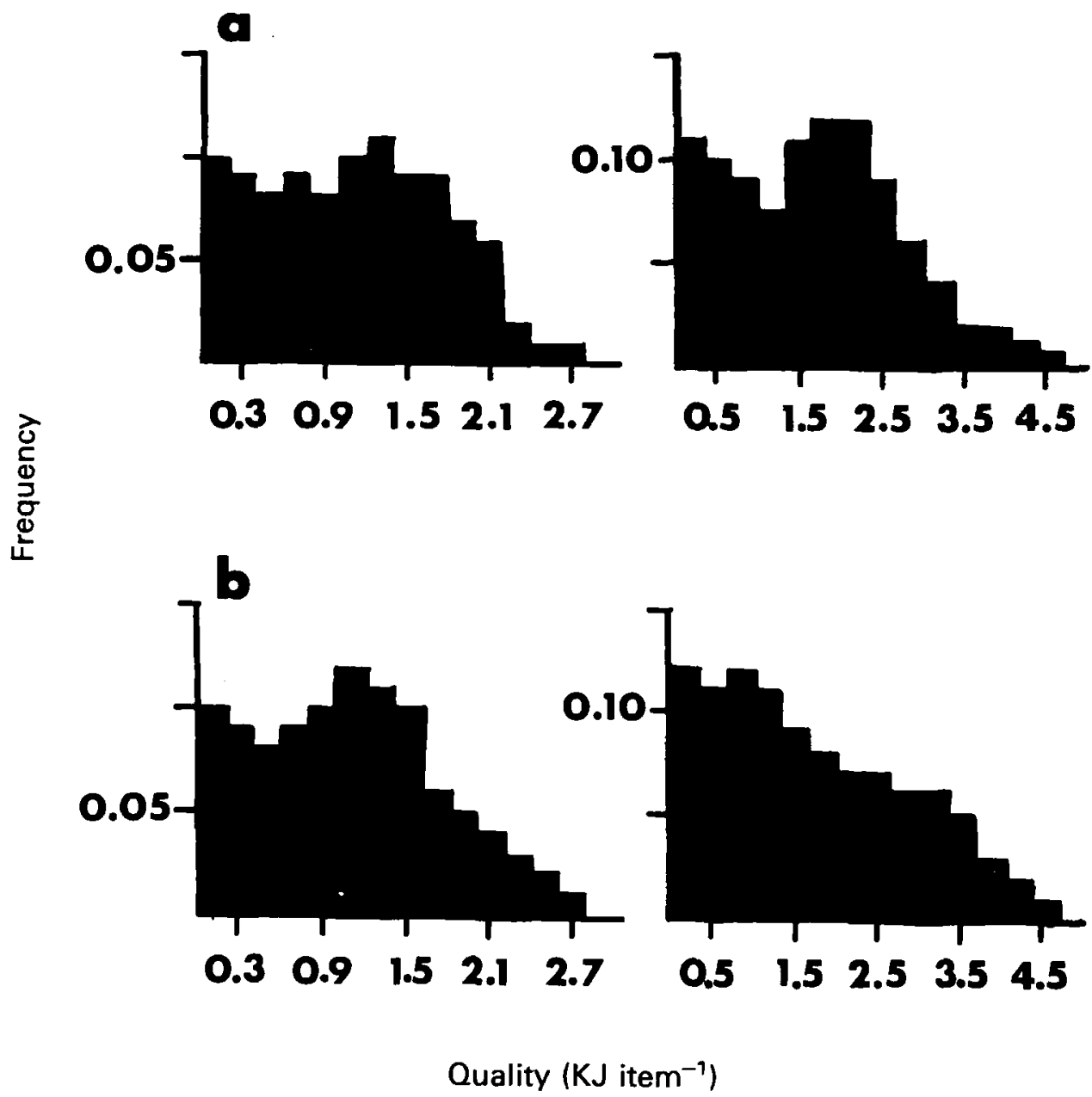

Figure 2. Examples of frequency distributions of twig quality in the Loring deer yard. Comparisons are for natural wintering area replicate 3 (a) and supplemental feeding area replicate 1 (b).

$1 \mathrm{~m}$ radius plots within $2 \mathrm{~m}$ above the snow surface and counting all coniferous twigs within $1 \mathrm{~m}$ radius areas on conifer trees within the reach of deer. Table 2 presents means and variances in encounter rates for deciduous and coniferous twigs for each replicate patch and time period.

Digestive time ( $d_{i}$, time per item)

Digestive time is a function of mean retention time (i.e. average time twigs from a feeding period remain in the rumen). I estimated that deer in the study area could digest (i.e. microbial decomposition and rumination) $4400 \pm 450$ twigs in a day ( $24 \mathrm{~h}$ period) given data presented in Schmitz (1990) and an average mean retention time of $36 \mathrm{~h}$ (Robbins, 1983). This translates into $0.32 \pm 0.03 \mathrm{~min} / \mathrm{twig}$. 
Table 2. Estimated encounter rates (twigs( $(\mathrm{min})^{-1}$ ) for deer feeding in deciduous and coniferous twig patches in the Loring study area. Values are means and SDs.

\begin{tabular}{|c|c|c|c|}
\hline Replicate & $\begin{array}{l}\text { Early } \\
\text { winter }\end{array}$ & $\begin{array}{l}\text { Mid- } \\
\text { winter }\end{array}$ & $\begin{array}{l}\text { Late } \\
\text { winter }\end{array}$ \\
\hline \multicolumn{4}{|c|}{$\begin{array}{l}\text { Deciduous twigs } \\
\text { (a) Supplemental feeding area }\end{array}$} \\
\hline 1 & $53(32)$ & $38(26)$ & $25(16)$ \\
\hline 2 & $56(45)$ & $43(29)$ & $22(17)$ \\
\hline 3 & $48(19)$ & $27(12)$ & $18(10)$ \\
\hline \multicolumn{4}{|c|}{ (b) Natural wintering area } \\
\hline 1 & $55(39)$ & $48(31)$ & $27(15)$ \\
\hline 2 & $48(23)$ & $29(15)$ & $20(13)$ \\
\hline 3 & $53(25)$ & $33(22)$ & $29(24)$ \\
\hline \multicolumn{4}{|c|}{$\begin{array}{l}\text { Coniferous twigs } \\
\text { (a) Supplemental feeding area }\end{array}$} \\
\hline 1 & $29(15)$ & $24(10)$ & \\
\hline 2 & $32(13)$ & $24(12)$ & \\
\hline 3 & $30(14)$ & $24(12)$ & \\
\hline \multicolumn{4}{|c|}{ (b) Natural wintering area } \\
\hline 1 & $30(11)$ & $23(9)$ & \\
\hline 2 & $31(17)$ & $19(10)$ & \\
\hline 3 & $29(13)$ & $21(8)$ & \\
\hline
\end{tabular}

\section{Daily feeding time $\left(T_{f}\right.$, min per day)}

In addition to these parameters, it was also necessary to estimate the maximum amount of time deer could spend foraging each day. For Equation 3a, I estimated $T_{f}$ in a related study (Schmitz, 1991) which examined how the thermal environment constrained the deer's ability to feed. Maximum total daily feeding time was $325 \mathrm{~min}$ in early and mid-winter and $310 \mathrm{~min}$ in late winter (Schmitz, 1991). These times were partitioned into feeding times for deciduous and coniferous browse by dividing the mean browse consumption (g dry mass daily, Schmitz, 1990) by the cropping time (g dry mass min $^{-1}$; Schmitz, 1990). For early, mid- and late winter respectively, the times were 321, 271 and 251 min daily for deciduous twigs and 4, 54 and 59 min daily for coniferous browse. For Equation $3 \mathrm{~b}$, maximum daily time was set by the amount of time deer could spend digesting food. Since ruminant herbivores have a continuous-flow digestive system, $T_{f}$ would be the entire 24 hour period (1440 min daily).

\section{Mean and variance in energy intake rate}

I estimated the energy intake rates for each day in $k=30$ consecutive day periods in early, mid and late winter using the previously measured foraging data in a computer algorithm which simulated sequential, random sampling by deer. The algorithm was:

1. Use the means and standard deviations of parameter estimates to generate normal distributions for maximum daily feeding (assuming a standard deviation of $10 \%$ for $T_{f}$ ), search, handling and digestive times.

2. Randomly select a maximum feeding time.

3. Randomly select a twig of quality $i$ from the frequency distribution for a patch. 
4. (a) If $i>r m$, add $i$ to the daily energy intake, randomly select a handling and search time and a digestive time and add the times to the respective daily feeding time budgets for search and handling or digestion.

(b) If $i<m$ then randomly select a search time and add it to the daily feeding time budget.

5. (a) If feeding time budget $<T_{f}$ then repeat steps 3-4.

(b) If feeding time budget $\geqslant T_{f}$ then repeat steps 2-4 until energy intakes are estimated for all $k$ feeding periods.

6. Calculate the mean and variance in energy intake rate for the 30-day period.

Expected energy intake rates were first calculated for the diet breadth containing twigs from the highest quality category only. Next the energy intake rate was calculated for the highest and second highest quality categories, and so forth, to simulate a broadening diet. Energy intake rates were estimated for diet breadths incremented by $0.1 \mathrm{KJ}(\mathrm{item})^{-1}$.

\section{Predicting optimal diet breadths}

The mean and variance estimates were used to calculate expected offspring production and starvation risk for different potential diet breadths. Expected offspring production was estimated using the linear regression equation presented in Fig. 1.

The appropriate time frame over which to estimate risk of starvation depends on the size of the forager and the level of energetic reserves. At one extreme is the long-term (e.g. weeks or months) where a forager's energy reserves are continuously depleted but the forager has no limit on feeding time (Houston and McNamara, 1985). The depletion rate of body stores depends on the nutrient intake achieved while feeding. Because nutrient intake varies, the forager will be uncertain about how long the reserves will last. In this case, foragers should eat any food item that yields a positive net energy return (Houston and McNamara, 1985). At the other extreme is the short-fall minimizer (Stephens and Charnov, 1982). In this case, nutrient reserves are depleted during a short non-foraging period (e.g. night time) and are replenished in the following feeding period. A forager with a positive expected energy budget (mean intake exceeds requirements) should select a diet with the mean and variance in energy intake rate that minimizes the risk of failing to meet the energetic requirements for survival during the feeding and subsequent non-feeding periods (Stephens and Charnov, 1982).

Generalist herbivores such as deer are too selective in their diet choices for continuous foraging to be plausible (Belovsky, 1981; Danell and Ericson, 1986; Vivas and Saether, 1987). Minimizing risk of starvation over the short term is also not a realistic strategy because deer can compensate for any short-term energetic shortfall by drawing more heavily on fat stores, at least in early and mid-winter when fat stores are not yet severely depleted. Deer obviously fall somewhere along a continuum between these two extreme strategies. However, we can approximate the risk of starvation by assuming deer will survive better to spring if they minimize the depletion rate of fat over the short-term. Minimizing short-term risk of an energetic shortfall should then have the same selective premium as minimizing starvation risk. Therefore, I approximated the risk of starvation by estimating the probability of a shortfall given the deer's average daily energy budget within each 30-day time period.

The risk of an energetic shortfall will be proportional to the fraction of energy intake rates, for a diet breadth, falling below requirements within a 30-day period. This can be estimated (Stephens and Charnov, 1982) using:

$$
D(m)=\phi(z(m))
$$

where $\phi($.$) is the cumulative standard normal distribution function and z(m)$ is determined by 


$$
\mathrm{z}(m)=\frac{R-E[\epsilon(m)]}{\sqrt{V[\epsilon(m)]}}
$$

Daily energy requirements $(R, \mathrm{KJ}$ daily) were estimated using the equation:

$$
R=1.8 a W^{0.75}-F-A
$$

where $W$ is body mass $(\mathrm{kg}), a$ is $316 \mathrm{KJ}\left(\mathrm{kg}^{0.75} \text { day }\right)^{-1}$ and $357 \mathrm{KJ}\left(\mathrm{kg}^{0.75} \text { day }\right)^{-1}$ for early and late winter (Moen, 1978), 1.8 is the increment for daily activity (Moen, 1978, 1985; Robbins, 1983), $F$ is the contribution of fat energy and $A$ is the contribution of energy from alternative foods (i.e. coniferous browse when consuming deciduous browse).

Fat energy was estimated to satisfy $30 \%$ of daily requirements in early winter and $25 \%$ in late winter (Mautz, 1978). Using data from Schmitz (1990), I estimated that $\boldsymbol{A}$ from deciduous browse was 7800 and $5380 \mathrm{KJ}$ daily when deer fed on coniferous browse in early and mid-winter respectively. $A$ from coniferous browse was 375,2700 and $3790 \mathrm{KJ}$ daily when deer fed on deciduous browse in early, mid- and late winter respectively.

Estimates of offspring production and starvation risk for different potential diet breadths were substituted into Equation 2 to predict the optimal diets for each treatment area, replicate food patch and time period.

\section{Measuring diets selected by deer}

The model (Equation 2) predicts the minimum twig quality $\left(\mathrm{KJ}(\text { item })^{-1}\right)$ a forager should include in its diet, i.e. the lower bound of the diet breadth. To compare deer behaviour with model predictions, I estimated the minimum twig quality $(\mathrm{KJ}$ (item)-1) deer selected in each treatment area, sampling period and replicate browse patch.

I examined deciduous twig selection in the same patches used to estimate distributions of available browse quality. I selected $18,1 \mathrm{~m}$ radius plots in each replicate deciduous patch. Plot sites were randomly selected. Coniferous twigs within the reach of deer did not occur in large contiguous patches. Therefore, I constructed artificial patches by placing conifer branches in large pots. Three replicate patches (3-4 pots per patch) were constructed in each experimental area. Conifer pots were placed away from deciduous patches.

I arbitrarily selected $30 \%$ of available twigs in each deciduous twig plot or coniferous twig pot. Twigs were selected randomly and tagged with flagging tape. Tagged twigs were measured from the tip to the junction with a main branch or a maximum of $20 \mathrm{~cm}$. Each tagged twig was measured for diameter at the junction with the main branch or $20 \mathrm{~cm}$ and notched at this point for future reference.

At the end of each sampling period, I remeasured the length of eaten, tagged twigs. This length was subtracted from the original length measurement to estimate the size of the portion eaten. I then clipped adjacent, uneaten twigs of the same species with equal diameters and lengths. The matching segments were dried at $60^{\circ} \mathrm{C}$ for $48 \mathrm{~h}$ and weighed to estimate dry mass consumed.

The matching bite and stubs of the matching twig and tagged twig were analysed using in vitro digestion in acid/pepsin. Digestibility of the browsed segment of the tagged twig $\left(D_{10}\right)$ was estimated indirectly using the ratio, $D_{\mathrm{tb}}=\left(D_{\mathrm{mb}} \times D_{\mathrm{tu}}\right) / D_{\mathrm{mu}}$, where $D_{\mathrm{mb}}$ is the matching bite digestibility, $D_{\mathrm{tu}}$ and $D_{\mathrm{mu}}$ are the digestibilities of stubs from the tagged and matching twig respectively. Each $D_{\mathrm{tb}}$ value was converted to an expected in vivo digestibility using a regression equation (Schmitz, 1990).

To estimate twig quality eaten ( $\mathrm{KJ}$ (item) $)^{-1}$ ), I multiplied the in vivo digestibility for each twig by its estimated dry mass ( $\mathrm{g}$ dry mass(item $)^{-1}$ ) and the gross energy content (KJ(g dry mass) $)^{-1}$ ) for the twig species. I obtained 80-100 eaten twigs from each food patch in each time period. 

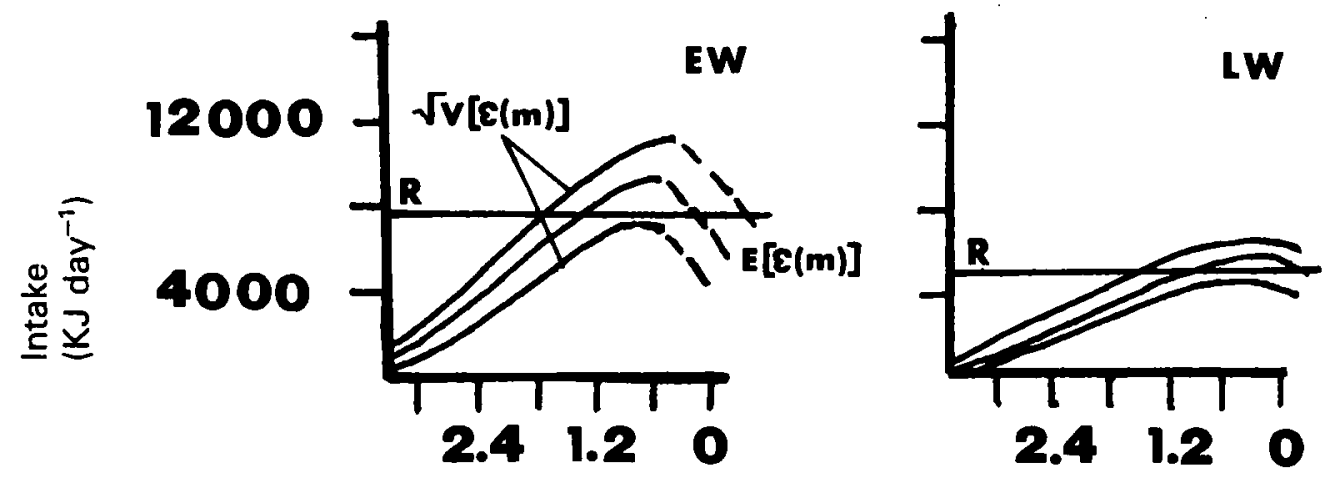

\section{Quality (KJ item $\left.{ }^{-1}\right)$}

Figure 3. Examples of estimated mean $E[\epsilon(m)]$ and standard deviation $\sqrt{V}[\epsilon(\mathrm{m})]$ in energy intake as a function of the lowest quality food item included in the diet (diet breadth) for early (a) and late (b) winter. The solid lines represent energy intake rates limited by search and handling time and the dashed lines represent intake rates limited by digestive time. The example is for natural wintering area replicate 3 . $R$ represents daily energy requirements for survival.
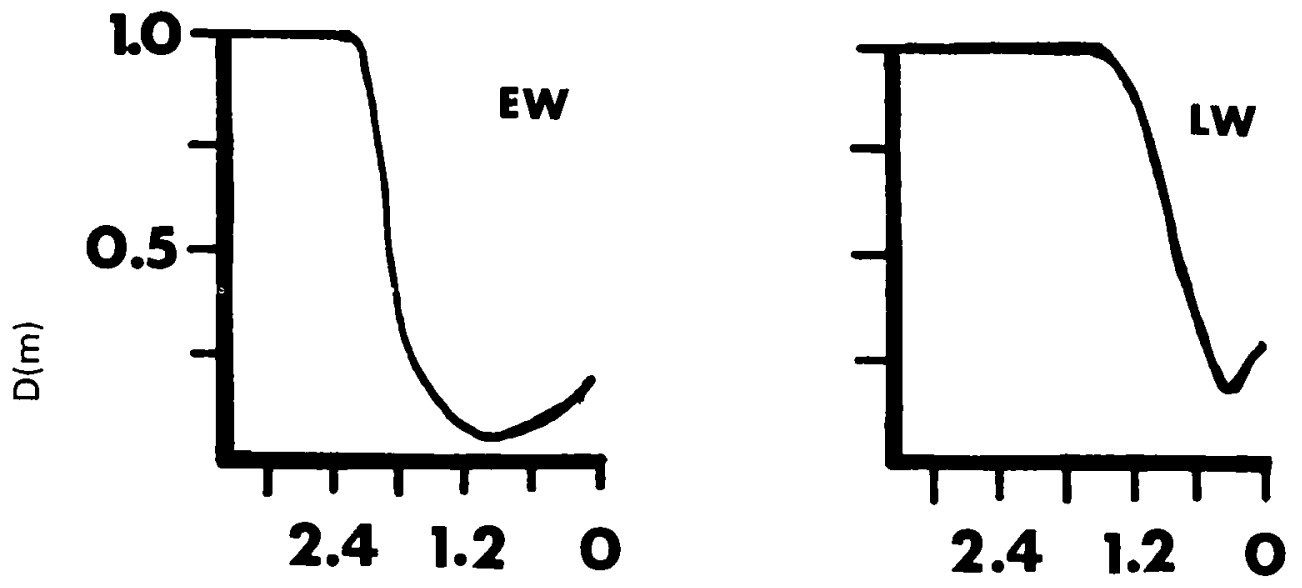

\section{Quality (KJ item $\left.{ }^{-1}\right)$}

Figure 4. Estimated starvation risk for different potential diet breadths (indexed by lowest quality food in the diet) in a 30 -day time period in early and late winter. Values are based on estimates of mean and standard deviation in energy intake rate relative to requirements from Fig. 3.

The minimum quality eaten in each patch was calculated as the mean of the lowest $10 \%$ of all twig qualities eaten ( $n=8-10$ samples). I chose $10 \%$ for two reasons. First, a lower fraction such as $5 \%$ would require a doubling of sampling effort to obtain a representative mean. This was not logistically possible. Second, recall that the diet breadth balancing risk and reproduction is predicted to be intermediate to risk minimizing and classical optimal diet breadths. Because my 
aim was to compare the observed diet breadths with predictions for all three alternatives, increasing the fraction (e.g. lowest $15 \%$ ) could result in a bias toward observed diet breadths that are narrower than the classical diet. Selecting the lowest $15 \%$ could artificially increase the chance of rejecting predictions of the classical model (i.e. a type I error).

\section{Model solutions and comparisons with deer behaviour}

Examples of mean and variance in energy intake rate for different diet breadths in relation to daily energy requirements are presented in Fig. 3. In general, energy intake rate in early winter was probably limited by search and handling time for diets containing higher quality food items and by digestive time for diets containing lower quality foods (Fig. 3). In late winter, energy intake rate appeared to be limited by search and handling time only because deer would not encounter and consume enough deciduous twigs to be limited by digestive time.
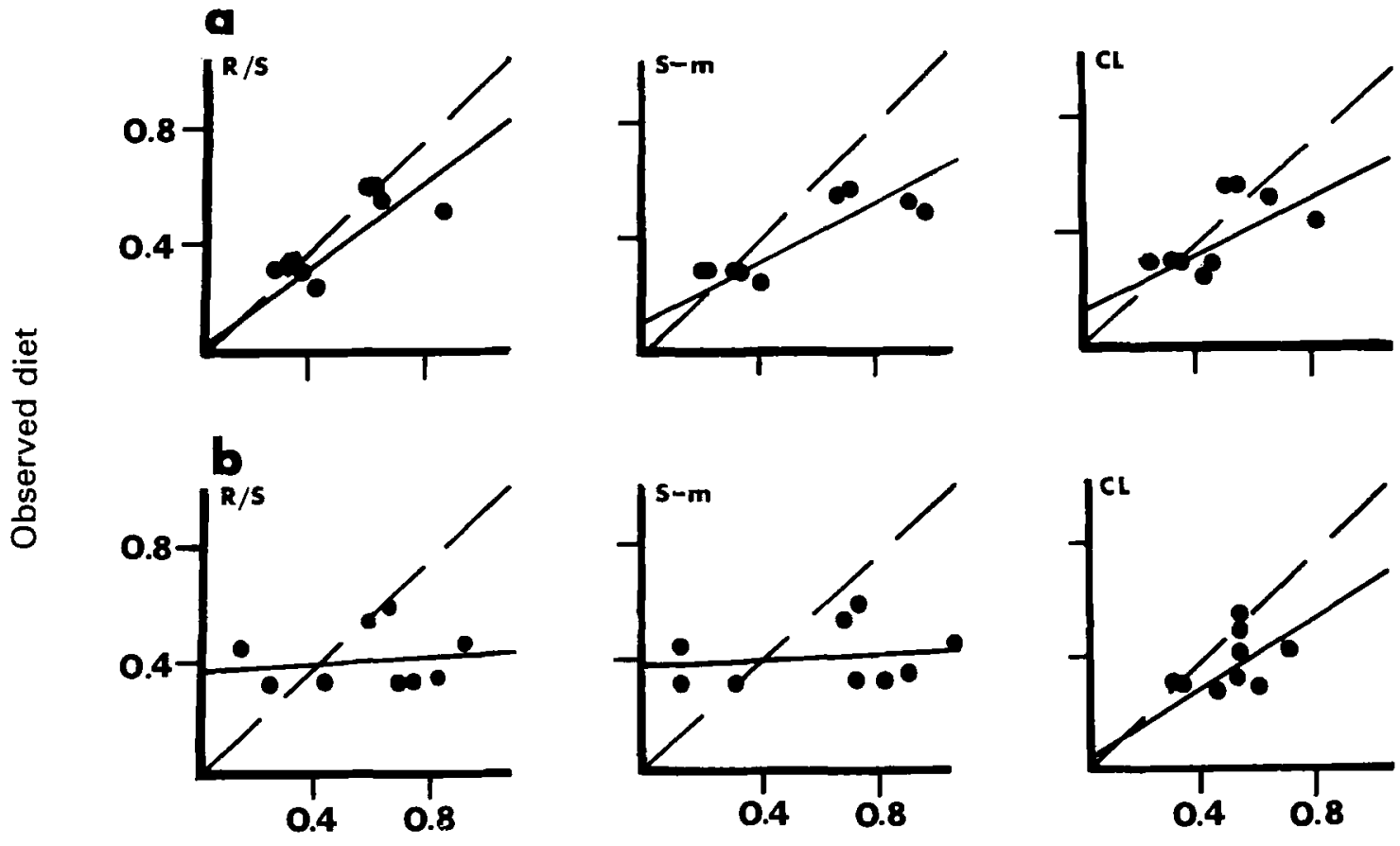

Predicted diet

Figure 5. Comparison of minimum deciduous twig qualities eaten by deer (observed diet) with minimum predicted values for diets balancing reproduction with starvation risk $(\mathbf{R} / \mathbf{S})$, diets minimizing starvation risk $(S-m)$ and diets maximizing expected energy intake (CL) in the natural wintering (a) and supplemental feeding (b) areas. Dashed, vertical lines represent perfect agreement between predicted and observed diets. Solid lines are regressions fit to the data. In (a) the model for the diet balancing reproduction with starvation risk was a less precise but more accurate predictor of observed diets $\left(Y=0.06+0.70 X, r^{2}=0.64, n=9\right.$, $p<0.05)$ than the model for the diet minimizing starvation risk $\left(Y=0.12+0.50 X, r^{2}=0.70, n=9\right.$, $p<0.05)$. The classical model did not adequately predict observed diets $\left(r^{2}=0.48, n=9\right.$, NS). In (b), only the classical model provided a significant relationship between predicted and observed diets $(Y=0.07+$ $\left.0.63 X, r^{2}=0.61, n=9, p<0.05\right)$. 

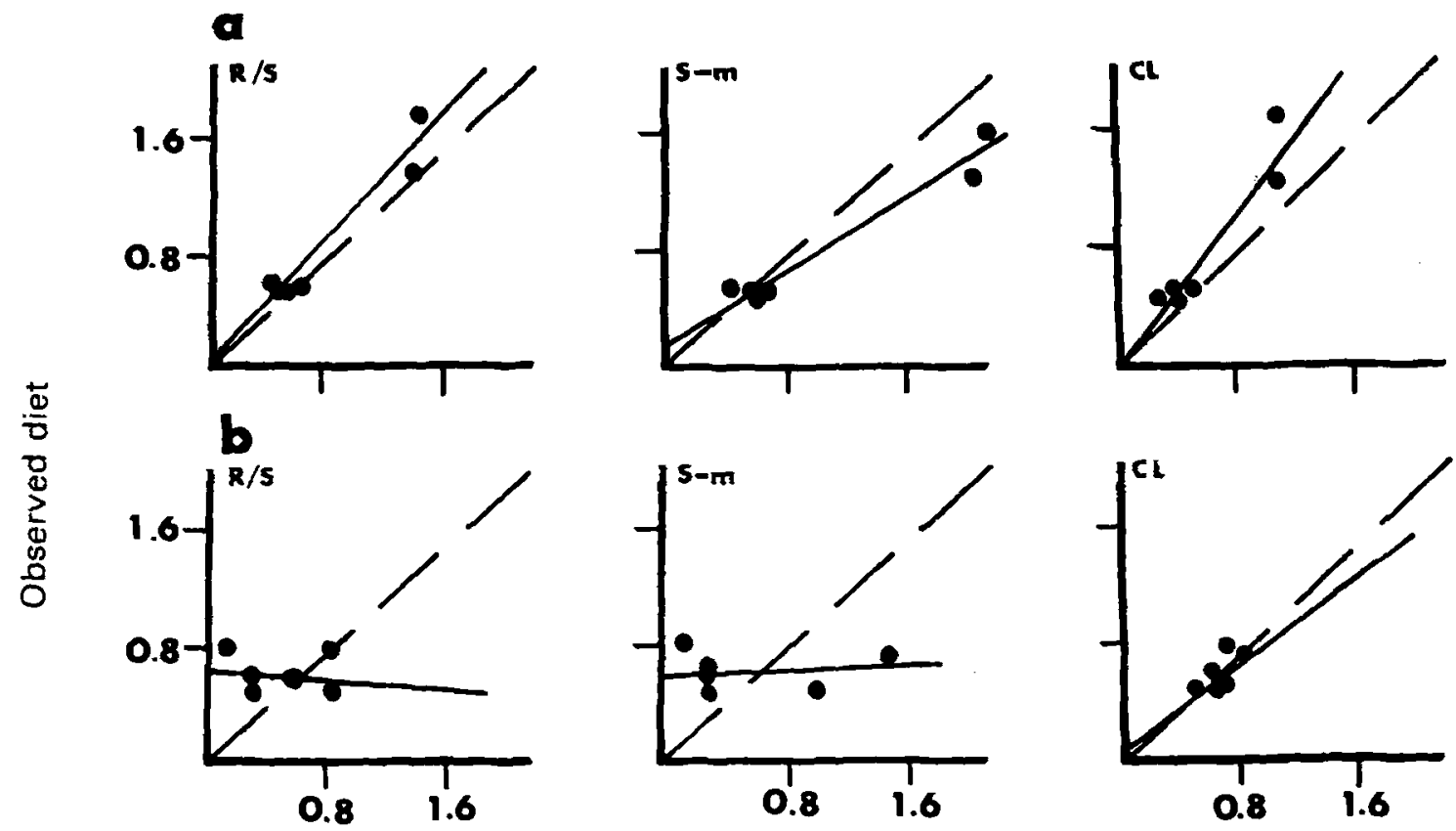

Predicted diet

Figure 6. Comparison of minimum coniferous twig qualities eaten by deer (observed diet) with minimum predicted values for diets balancing reproduction with starvation risk $(\mathbf{R} / \mathbf{S})$, diets minimizing starvation risk $(S-m)$ and the classical optimal diet $(C L)$ in the natural wintering (a) and supplemental feeding (b) areas. Dashed, vertical lines represent perfect agreement between predicted and observed diets. Solid lines are regressions fit to the data. In (a), all three models had equal precision (all $r^{2}=0.96, n=6, p<0.05$ ). The model for the diet balancing reproduction with starvation risk was a more accurate predictor of observed diets $(Y=0.03+1.03 X)$ than either the model for the diet minimizing starvation risk $(Y=0.18+0.61 X)$ or the classical diet mudel $(Y=1.32 X-0.003)$. In (b), none of the models provided a significant relationship between predicted and observed diets although the classical foraging model predictions were in the hypothesized direction $(r=0.65, n=6, p>0.05$ ).

Examples of the estimated risks of energetic shortfall for different potential diet breadths are presented in Fig. 4. Because of twig depletion, the diet breadths minimizing starvation risk in late winter were identical with the diet breadths maximizing mean energy intake rates (Figs 3 and 4).

The predicted and observed diets are presented in Fig. 5 for deciduous twigs and in Fig. 6 for coniferous twigs. For the natural wintering treatment, the diet balancing expected reproduction with starvation risk appeared to best predict observed deciduous and coniferous diets (Figs 5 and 6) as judged by the correlation coefficient and the magnitude of the slope and intercept of the regression equation. For the supplemental feeding treatment, I estimated the diet breadths balancing expected offspring production with starvation risk and diet breadths minimizing - starvation risk by assuming supplemental feed was not provided and by using the same daily energy requirements and daily feeding times used for the Natural wintering area. In this area, observed deciduous diets matched most closely predictions of the classical foraging model (Fig. $5)$. Although the trend between predicted and observed coniferous diets most closely matched the classical model predictions, the relationship was not significant (Fig. 6). 
Table 3. Test for differences in variances in bite sizes between naturally wintering and supplementally fed deer in the Loring study area. Variance is average for each time period $(n=3$ replicate food patches).

\begin{tabular}{lllll}
\hline $\begin{array}{l}\text { Time } \\
\text { period }\end{array}$ & $\begin{array}{l}\text { Natural } \\
\text { wintering }\end{array}$ & $\begin{array}{l}\text { Supplementally } \\
\text { fed }\end{array}$ & $F$-ratio & $p$-value \\
\hline & & Deciduous twigs & & \\
Early winter & 0.016 & 0.013 & 1.231 & $>0.05$ \\
Mid-winter & 0.020 & 0.015 & 1.333 & $>0.05$ \\
Late winter & 0.026 & 0.036 & 1.385 & $>0.05$ \\
& & & & \\
Early winter & 0.070 & 0.119 & 1.700 & $>0.05$ \\
Mid-winter & 0.237 & 0.163 & 1.450 & $>0.05$ \\
\hline
\end{tabular}

The estimated minimum qualities eaten by supplementally fed deer ( $\mathrm{KJ}$ (item) $)^{-1}$ ) approached the lower limit of the distribution of available qualities (Fig. 2). Because I estimated the food quality eaten by deer as the product of bite size $\left(\mathrm{g}\right.$ dry $\left.(\mathrm{item})^{-1}\right)$ and item digestible energy content $\left(\mathrm{KJ}(\mathrm{g} \text { dry mass })^{-1}\right)$, these minimum values could have arisen because deer simply nibbled on twigs. Consequently, any agreement between predicted and observed diets could be fortuitous, given the way observed diets were measured. If this were so, however, it would be expected that the variance in bite sizes for deer in supplemental feeding sites would be significantly smaller than in natural wintering sites. This is because foragers selecting diets according to model predictions should include items with the minimum predicted quality or better whenever they are encountered. By nibbling, deer would be consuming a much smaller range of food item qualities.

I estimated the variance in bite sizes for all replicates and time periods. I then calculated the average variance for each time period in natural wintering and supplemental feeding areas respectively. These values are presented in Table 3. I used an $F$-ratio (Ostle and Mensing, 1975) to test for homogeneity of variances between the two areas in each time period. In each case there was no significant difference between variances $(p>0.05)$ indicating that deer in the supplemental feeding area did not simply nibble.

\section{Discussion}

Classical optimal foraging models (Stephens and Krebs, 1986) assume that foragers select their diets on the basis of mean nutrient intake rate and that variation in nutrient intake rate is negligible or unimportant (Caraco, 1980; Stephens and Krebs, 1986). This assumption has been considered unrealistic for animals in natural environments. Variability can introduce a risk that the nutrient intake rate obtained in a feeding period will fall below requirements for survival (Real and Caraco, 1986; Stephens and Krebs, 1986). Consequently, foragers should respond to both mean and variance in nutrient intake rate when selecting their diets.

Most of the variance in energy intake rate for white-tailed deer in winter arises from four factors:

1. Food items have a wide range of nutrient contents $\left(\mathrm{KJ}(\mathrm{item})^{-1}\right.$, Fig. 1). When randomly sampling food items in a patch, there is no guarantee that a forager will obtain items with the same quality among consecutive foraging periods.

2. Daily feeding time is limited by the thermal environment (Schmitz, 1991). Because 
temperatures vary among consecutive days in winter, the amount of time deer can spend feeding will vary. Consequently, the total number of food items a deer consumes will vary among feeding periods.

3. The abundance of food varies on a local scale resulting in variable encounter rates with food items.

4. Handling or digestive time for food items is variable. When handling a food item, the forager must forgo searching for and handling new food items. Because daily feeding time is limited, variable handling times will cause the number of food items eaten in each feeding period to vary.

The magnitude of variation in daily energy intake for different potential diets ranges from $5 \%$ to $40 \%$ of the mean. These values are sufficient to attach a risk of starvation to all potential diet breadths (Fig. 4). Consequently, mean and variance in energy intake rate can be an important factor in decision-making by animals in natural environments.

In this study deer had to choose among combinations of mean and variance in energy intake rate represented by different potential diet breadths. In the Natural wintering area, deer appeared to select the diet breadth that balanced starvation risk and offspring production, as hypothesized (Figs 5 and 6). These predicted diet breadths are, however, only optimal for reproductive females. But non-reproductive individuals should tend to select risk minimizing diet breadths (Schmitz and Ritchie, 1991) which will be more narrow than diets for reproductive females (Figs 5 and 6 ). Thus item qualities selected by non-reproductive individuals would be subsumed in a measure of the distribution of items selected by reproductive females. It is impossible to distinguish between diet breadths selected by individuals in each sex/age group without following them in the field individually. Nevertheless, the observed diets were likely measured for the majority of the population in the natural wintering area since more than $50 \%$ of all individuals observed there were potentially reproductive adult females (O. J. Schmitz, unpublished observations).

In the supplemental feeding area, variance in energy intake rate became unimportant for diet selection because starvation risk was eliminated. As expected, observed deciduous diets matched predictions of the classical foraging model in this environment (Fig. 5). This diet breadth was optimal for all individuals in the supplemental feeding area, regardless of sex or age, because a linear offspring production function guarantees that the diet breadth maximizing expected fitness is identical with the fitness for the diet breadth maximizing expected energy intake rate (Schmitz and Ritchie, 1991).

In conclusion, it appears that the magnitude of variance in energy intake rate was sufficient to introduce a risk of starvation for deer in natural environments. Deer also appeared to exhibit plasticity in their diet selection in response to temporal and spatial changes in perceived risks and gains. In the natural wintering area, deer selected diets that appeared to balance gains in fitness due to reproduction with losses in fitness due to energetic shortfalls. When starvation risk was eliminated, deer tended to select diet breadths that simply maximized their mean energy intake rate.

\section{Acknowledgements}

I thank S. Dosser, H. Schmitz and M. E. Ritchie for helping with the field work and lab analyses and G. E. Belovsky, T. Caraco, M. E. Ritchie, D. R. Voigt, and E. E. Werner for helpful comments. This study was funded by a Renewable Resources Research Grant from the Ontario Ministry of Natural Resources (OMNR) and by a Research Fellowship and a Predoctoral Dissertation Fellowship from the University of Michigan, Rackham Graduate School. The Wildlife Research Section of the OMNR provided logistical support. 


\section{References}

Baker, D. L. and Hobbs, N. T. (1987) Strategies of digestion: digestive efficiency and retention time of forage diets in montane ungulates. Can. J. Zool. 65, 1978-84.

Baker, D. L., Johnson, D. E., Carpenter, L. H., Wallmo, O. C. and Gill, R. B. (1979) Energy requirements of mule deer fawns in winter. J. Wildl. Manage. 43, 162-9.

Barkan, C. P. L. (1990) A field test of risk-sensitive foraging in black-capped chickadees (Parus atricapillus). Ecology 71, 391-400.

Belovsky, G. E. (1981) Food plant selection by a generalist herbivore: the moose. Ecology 62, 1020-30.

Belovsky, G. E. (1984) Herbivore optimal foraging: a comparative test of three models. Am. Nat. 124, 97115.

Caraco, T. (1980) On foraging time allocation in a stochastic environment. Ecology 61, 119-28.

Caraco, T. and Gillespie, R. G. (1986) Risk-sensitivity: foraging mode in an ambush predator. Ecology 67, $1180-5$.

Clutton-Brock, T. H., Guiness, F. E. and Albon, S. D. (1982) Red Deer: the Behavior and Ecology of Two Sexes, University of Chicago Press, Chicago, IL, USA.

Danell, K. and Ericson, L. (1986) Foraging by moose on two species of birch when these occur in different proportions. Holarct. Ecol. 9, 79-84.

Hanley, T. A. and McKendrick, J. D. (1985) Potential nutritional limitation for black-tailed deer on Admiralty Island, southeast Alaska. J. Wildl. Manage. 49, 103-14.

Holter, J. B., Urban W. E. and Hayes, H. H. (1979) Predicting energy and nitrogen retention in young white-tailed deer. J. Wildl. Manage. 43, 880-8.

Houston, A. and McNamara, J. (1985) The choice of two prey types that minimizes the probability of starvation. Behav. Ecol. Sociobiol. 17, 135-41.

Hughes, R. N. (1979) Optimal diets under the energy maximizing premise: the effects of recognition time and learning. Am. Nat. 113, 209-21.

Langeneau, E. E. and Lerg, J. M. (1976) The effects of winter nutritional stress on maternal and neonatal behavior of penned white-tailed deer. Appl. Anim. Ethol. 2, 207-23.

Mautz, W. W. (1978) Sledding on a bushy hiliside: the fat cycle in deer. Wildl. Soc. Bull. 6, 88-90.

Moen, A. N. (1978) Seasonal changes in heart rates, activity, metabolism and forage intake of white-tailed deer. J. Wildl. Manage. 42, 715-38.

Moen, A. N. (1985) Energy metabolism of deer in relation to environmental variables. R.S.N.Z. Bull. 22, 439-45.

Ostle, B. and Mensing, R. W. (1975) Statistics in Research, 3rd edn. Iowa State University Press, Ames, IA, USA.

Owen-Smith, N. and Novellie, P. (1982) What should a clever ungulate eat? Am. Nat. 119, 151-78.

Potvin, F. and Huot, J. (1983) Estimating carrying capacity of a white-tailed deer wintering area in Quebec. J. Wildl. Manage. 47, 463-75.

Real, L. A. (1981) Uncertainty and pollinator-plant interactions: the foraging behavior of bees and wasps on artificial flowers. Ecology 62, 20-6.

Real, L. A. and Caraco, T. (1986) Risk and foraging in stochastic environments. Ann. Rev. Ecol. Syst. 17, $371-90$.

Robbins, C. T. (1983) Wildlife Nutrition, Academic Press, London.

Robinson, W. L. (1962) Social dominance and physical condition among penned white-tailed deer fawns. $J$. Mamm. 43, 462-9.

Schmitz, O. J. (1990) Management implications of foraging theory: evaluating deer supplemental feeding. J. Wildl. Manage. 54, 522-32.

Schmitz, O. J. (1991) Thermal constraints and optimization of winter feeding and habitat choice in whitetailed deer. Holarct. Ecol. 14, 104-11.

Schmitz, O. J. and Ritchie, M. E. (1991) Optimal diet selection with variable nutrient intake: balancing reproduction with risk of starvation. Theor. Pop. Biol. 39, 100-14.

Schoener, T. W. (1974) The compression hypothesis and temporal resource partitioning. Proc. Natl. Acad. Sci. USA 71, 4169-72. 
Spalinger, D. E. (1980) Mule deer habitat evaluation based upon nutritional modelling. MA thesis, University of Nevada, Reno.

Spalinger, D. E., Robbins, C. T. and Hanley, T. A. (1986) The assessment of handling time in ruminants: the effect of plant chemical and physical structure on the rate of breakdown of plant particles in the rumen of mule deer and elk. Can. J. Zool. 64, 312-21.

Stephens, D. W. and Charnov, E. L. (1982) Optimal foraging: some simple stochastic models. Behav. Ecol. Sociobiol. 10, 251-63.

Stephens, D. W. and Krebs, J. R. (1986) Foraging Theory. Princeton University Press, Princeton, NJ, USA.

Tilley, J. M. A. and Terry, R. A. (1963) A two-stage technique for the in vitro digestion of forage crops. $J$. Brit. Grassl. Soc. 18, 104-11.

Townsend, T. W. (1973) Factors affecting individual rank in the social hierarchy of penned white-tailed deer (Odocoileus virginianus borealis). PhD thesis, University of Guelph, Guelph, ON, Canada.

Verme, L. J. (1962) Mortality of white-tailed deer fawns in relation to nutritional plane. In Proceedings of the National White-tailed Deer Disease Symposium 1, 15-38.

Verme, L. J. (1963) Effects of nutrition on growth of white-tailed deer fawns. Trans. North Am. Wildl. Nat. Resource Conf. 28, 431-43.

Verme, L. J. (1965) Reproduction studies on penned white-tailed deer. J. Wildl. Manage. 29, 74-9.

Verme, L. J. (1967) Influence of experimental diets on white-tailed deer reproduction. Trans. North Am. Wildl. Nat. Resource Conf. 32, 405-20.

Vivas, H. J. and Saether, B. E. (1987) Interactions between a generalist herbivore the moose Alces alces and its food resources: an experimental study of winter foraging behavior in relation to browse availability. J. Anim. Ecol. 56, 509-20. 